\title{
Optimization of torrefaction conditions for high energy density solid biofuel from oil palm biomass and fast growing species available in Malaysia
}

\begin{abstract}
Without appropriate treatment, lignocellulosic biomass is not suitable to be fed into existing combustion systems because of its high moisture content, low bulk energy density and difficulties in transport, handling and storage. The aim of this study was to investigate the effects of torrefaction treatment on the weight loss and energy properties of fast growing species in Malaysia (Acacia spp., and Macaranga spp.) as well as oil palm biomass (oil palm trunk and empty fruit bunch). The lignocellulosic biomass was torrefied at three different temperatures 200,250 and $300{ }^{\circ} \mathrm{C}$ for 15,30 and $45 \mathrm{~min}$. Response surface methodology was used for optimization of torrefaction conditions, so that biofuel of high energy density, maximized energy properties and minimum weight loss could be manufactured. The analyses showed that increase in heating values was affected by treatment severity (cumulated effect of temperature and time). Our results clearly demonstrated an increased degradation of the material due to the combined effects of temperature and treatment time. While the reaction time had less impact on the energy density of torrefied biomass, the effect of reaction temperature was considerably stronger under the torrefaction conditions used in this study. It was demonstrated that each biomass type had its own unique set of operating conditions to achieve the same product quality. The optimized torrefaction conditions were verified empirically and applicability of the model was confirmed. The torrefied biomass occurred more suitable than raw biomass in terms of calorific value, physical and chemical properties. The results of this study could be used as a guide for the production of high energy density solid biofuel from lignocellulosic biomass available in Malaysia.
\end{abstract}

Keyword: Torrefaction; Oil palm biomass; Fast growing species; High energy density; Solid biofuel 